Marharyta Chepeliuk

Department of International Economic Relations

Simon Kuznets Kharkiv National University of Economic, Kharkiv, Ukraine

E-mail: chepeliuk.margo@gmail.com

ORCID: https://orcid.org/0000-0002-1949-4747

Kateryna Kutsenko

Department of International Economic Relations

Simon Kuznets Kharkiv National University of Economic, Kharkiv, Ukraine

E-mail: ekaterina.markina994@gmail.com

ORCID: https://orcid.org/0000-0002-2080-6218

\title{
The development of high-tech business in Ukraine
}

\begin{abstract}
Both technology and business are changing in the world. The new paradigm of the world is emerging in the form of systems, affecting all aspects of the activities of society and market players. The scale and complexity of transformation will be different from what humanity has experienced before. It is not yet possible to predict with great precision how it will unfold, but one thing is clear: the answer must be integrated and comprehensive, from the public and private sectors in scientific community, business and society. In the new economic environment, economic agents have to go through the processes of digital transformation that are necessary to improve. The purpose of the article is to define the main directions of the development of digitalization and to analyse Ukraine's place in the world by the level of development of digitalization. Methodical tools of the study were methods of analysis and synthesis, deduction and induction, search for causal relationships. The article presents the results of empirical analysis of the main trends in the Ukrainian market during the pandemic and their relationship with the processes of digitalization. The article analyzes the development trends and the size of the digital economy in Ukraine and in other countries of the world. Key numerical trends have been identified that will determine the direction of this type of economy. It has been proved that digitalization must be carried out in accordance with the principles of equal access, benefit creation, economic growth, the promotion of the information society and the orientation towards cooperation. The advantages of the digitalization of Ukrainian economy are presented, as well as the threats and risks that will arise from this process are indicated.
\end{abstract}

\author{
Keywords \\ Digitalization, digital \\ economy, strategic \\ management, \\ transformation, innovation, \\ development, challenges, \\ strategy
}

JEL: F63, M54, O33

DOI: https://doi.org/10.30525/2500-946X/2021-1-10

\section{Introduction}

The modern world has already taken the first step towards new technological, economic and social sciences. But the challenges of modern corporate society are much more complex. These are changes in the world economic system that have led to a complete overhaul of our systems and the introduction of new economic and social policies. At the same time, the technical paradigm is changing, the types of governance and social norms are changing, and there are dramatic changes in the population. But the problem is not that a new type of mutation is happening. The problem is that these changes are happening very quickly - not a thousand years later as an agrarian, not a century later as an industrial process, but a few years later.

In the new context, the country will also benefit from digital technologies, in which all sectors of the economy grow, connect, improve and grow.

Thus, the developing role of many countries, including Ukraine, is linked to unrestricted access and the transformation of new forms of economic development that take account of the use of intellectual and human skills.

In order for the country to dominate the global computer economy, special attention must be paid to production, innovation and employment opportunities in the country.
For each country, the production and maintenance of technical skills is an important component of economic development, employment and economic growth and development.

\section{Status of the digital economy in Ukraine}

Ukraine is changing towards Industry 4.0. The movement "Industry 4.0 in Ukraine" has been established, the Association of Industrial Automation of Ukraine pays great attention to these issues. At the mentioned industrial exhibition in Hannover, IT enterprise's representatives noted with satisfaction that the module "Manufacture" and other modules of ERP-system of IT enterprise already solve the problems of Industry 4.0 , and make it more efficient than similar systems of competitors. And at a forum in Hong Kong in 2016, representatives of 200 industry technology incubators of Industry 4.0 were surprised to learn that some of the problems they were just beginning to face have been already solved by the IT enterprise and its specialists are ready to announce the results achieved.

Today, Ukraine is more than a decade behind the developed countries in innovation. It should be said that during this time the global market has managed to fly around about five generations of technologies. The most critical 
issue in our country remains the lack of access to technology and the gap between it and industry. In large enterprises, a conservative and archaic approach to the conduct of business still remains. Say the transportation of gas or heat is still measured in cubic meters, not calories. Existing Automated Production Management Systems (MES) are secondary. The diffusion and consolidation of technology is rooted in infrastructural constraints: terrible roads, low Internet speed, regulatory obstacles that suppress any initiative or overshadow it because of their punitive intent (Billon, LeraLopez, Marco, 2010).

According to GII rankings, Ukraine holds positions on the quality of human capital. Here we are talking about the wide demographic coverage of higher education, the number of qualified employees in knowledge-intensive industries. For example, about 90,000 employees work in the IT outsourcing sector and according to the forecasts of the association "IT Ukraine", in the next 2-3 years their number will increase to 200,000 .

De facto, IT is the only sphere that is integrated into the global market. But it is generally far from Ukrainian industry. The process of industrial development is dominated by specialists in narrow production technologies and industrial management systems. At the same time Ukrainian system integrators of control systems, engineering companies, machine builders are well known in CIS, but not in the world. In many ways, they are conservative and lag behind IT and the global rate of innovation.

The old industries retained qualified engineers. Ukrainian science, represented by universities and academies of sciences, cannot be depreciated. Admittedly, cooperation between universities and industry remains a weakness. Academic science is guilty of excessive theorizing, far from life. The situation can fix the order from business. At the same time, the scientific community needs people who can turn scientific discoveries into practical developments (Venkitachalam, Willmott, Nambisan, Wright, Feldman, 2016).

Startups compete with science, which, by the way, has a lot of people in the scientific community. These are 480 companies that are serviced and technically ready for innovative development. In addition, there have been successful examples of interdisciplinarity, such as AgTech, which successfully crosses the agrosphere with high technology. The mismatch between industry, software companies, science, the outdated environment and the lack of value chains between them adversely affects the investment attractiveness of individual market participants, all sectors and the country as a whole.

\section{Findings}

The accelerated de-industrialization of Ukraine can be illustrated by comparing the economies of Ukraine and Poland, in particular the dynamics and structure of exports. Poland outperformed Ukraine in industries where Ukraine was stronger, such as engineering and aviation. Today, Poland exports mainly high-value-added products and Ukraine exports raw materials (Briel, Davidsson, Recker, 2018).

This means that Ukraine is not ready for the introduction of Industry 4.0. Moreover, the implementation of Industry 3.0 in Ukraine is not yet complete. Even the level of automation in Ukrainian industry is still below average. In metallurgy, for example, it is about 50 percent. So, the problem, i.e. the digital leap, where companies urgently need to go from 3.0 to 4.0 , is that the country is emerging very quickly. The level of digitalization of the Ukrainian economy varies considerably from sector to sector. In such areas as financial services, communication services, logistics, Ukrainian companies use advances in information technologies as widely as foreign competitors (Sondergaard, 2019; Casselman, Giones, Brem, 2007).

At the same time, the intensity of use of digital technologies (as well as everything associated with them automation, robotics) is very low in several industries (for example, mining). This situation accounts for a significant productivity gap in the sector.

It is estimated that in Ukraine the level of expenditure of enterprises on the development of new technologies and products and the state of investment in innovation is absolutely unsatisfactory and catastrophic compared to world leaders, if you look at it from the perspective of the country's development prospects. According to State Statistics Service of Ukraine, 10,954 million UAH. 400-450 million USD was spent on research and development of Ukrainian enterprise in 2017. Whereas according to the "Global Innovation 100" report, the combined R\&D spending of the world's top 1,000 companies in 2017 reached 702 billion USD (Strategy Partners, PWC).

The $R \& D$ costs of Amazon were 16.1 billion USD; Volkswagen spent 12.5 billion USD. State Statistics Service of Ukraine points out that there is a direct correlation between the size of an enterprise and its level of innovation, because innovation requires a certain number of personnel involved in research and development, innovating. The highest share of technologically active enterprises among large enterprises was 31.4 per cent and 28.1 per cent, respectively.

Suppliers of equipment, materials, components or software $(26.1 \%)$ and consumers $(13.7 \%)$ remain the most

TABLE 1 Comparison of the dynamics and structure of exports of Ukraine and Poland, billion USD

\begin{tabular}{|c|c|c|c|c|}
\hline & Poland & Growth & Ukraine & Growth \\
\hline \multicolumn{5}{|c|}{ Export } \\
\hline 1993 & 17,5 & & 16 & \\
\hline 2020 & 325 & 19 times & 59 & 3 times \\
\hline \multicolumn{5}{|c|}{ Export structure } \\
\hline Export of equipment & \multicolumn{2}{|c|}{51} & \multicolumn{2}{|c|}{4.5} \\
\hline Export of motor transport & \multicolumn{2}{|c|}{31} & \multicolumn{2}{|c|}{0.7} \\
\hline Export of metals & \multicolumn{2}{|c|}{21} & \multicolumn{2}{|c|}{11.4} \\
\hline Export of chemical products & \multicolumn{2}{|c|}{15} & \multicolumn{2}{|c|}{1.75} \\
\hline Export of plant products & \multicolumn{2}{|c|}{5} & \multicolumn{2}{|c|}{9.48} \\
\hline
\end{tabular}


important partners of innovative collaborative enterprises. The share of enterprises cooperating with scientific organizations (consultants, commercial laboratories, universities and other universities and research institutes) in Ukraine is only $8.4 \%$.

Suppliers of equipment, materials, components or software $(26.1 \%)$ and consumers $(13.7 \%)$ remain the most important partners of innovative collaborative enterprises. The share of enterprises cooperating with scientific organizations (consultants, commercial laboratories, universities and other universities and research institutes) in Ukraine is only $8.4 \%$ (Strategy Partners, PWC).

According to data of State Statistics Service of Ukraine on 2018 innovation activity in industry accounted for only $16.4 \%$ of enterprises. In developed countries, the share of innovative enterprises is four to five times higher, accounting for 50 to $60 \%$ of the total number of enterprises.

The share of innovative enterprises in the EU on average is $51 \%$. Belgium has the highest level of $68 \%$, Portugal has $67 \%$, Finland has $65 \%$, Germany has $64 \%$ and Luxembourg has $64 \%$. The lowest is in Romania - $10 \%$ and in Poland - 22 \%. In Ukraine, only $3.9 \%$ of enterprises spent on research and development (internal and external). The share of innovation in total output sold has been in the range of $6-7 \%$ for many years. The knowledge intensity of GDP in Ukraine declined almost threefold between 1990 and 2019. It is less than 1\% (Strategy Partners, PWC).

However, the low innovation performance of Ukrainian enterprises does not mean that they do not have sufficient funds to carry out the innovation activity. Enterprise research expenditure can be compared, for example, to business expenditure on political parties, football clubs, bribes and the like. This pattern of expenditure only indicates that enterprises have resources for research and development but choose other areas of expenditure. So, the expenses of the Ukrainian manufacturer on innovation do not have the primary need for business. The technical backwardness of the enterprise is not a critical problem for the producer.

In order to meet such challenges, Ukraine has proposed five principles for action:

Full synchronization with world trends 4.0 in particular, applying the principle of separation between IoT and Industry 4.0 .
Focus on high-value-added activities: The parti-cipants jointly identify these industries and work together to quickly introduce 4.0 Technologies.

Specific actions in certain directions: The movement participants jointly define the formats and mechanisms of interaction, shape the management structure and define specific courses of action. The priorities are as follows:

Education of market participants on 4.0 Technologies and growth of industrial culture;

Cooperation with European and world associations in the area of 4.0;

Joint development of sectoral road maps;

Growth and integration of technology innovators in projects 4.0;

Comprehensive support for the establishment and development of high-tech and innovation clusters (Henriette, Mondher, Boughzala, 2015).

The leadership and responsibility of the IT sector must demonstrate not only technological advantage but also sufficient integration and communication capabilities to effectively bring together the various actors involved in industry. IT should also demonstrate sufficient willingness and ambition in the direction of "back to home" - to channel its export potential to the realization of internal Ukrainian tasks.

It is no longer about "back to USSR", that is, it is not worth to «save» giants of the post-Soviet industry, where the post-Soviet culture still dominates. Since the "Industry 4.0" movement is aimed at the development of those who really want to integrate more quickly into the global world, priority is development of small and medium-sized businesses, and innovative startups (Strategy Partners, PWC).

The impact of digitalization is determined by the value added that digital creates for each branch of the economy or sector of life at the macro level or for a particular product or service at the micro level. At the macro level, this value added represents a corresponding share of GDP growth (\% of total GDP). It is this cumulative share that is the digital economy as part of the traditionally analog economy (Polozhikhina, 2018).

That is why the digital economy is not so much the ICT industry represented by ICT companies, but all the other industries and sectors of life that are users of ICT

TABLE 2 Share of some digital services in Ukraine and EU (by the end of 2020), \%

\begin{tabular}{|c|c|c|}
\hline Digital service & Ukraine & EU \\
\hline E-commerce in retail trade & 4 & 7 \\
\hline Organizations that use CRM systems & 10 & 33 \\
\hline People who buy online & 23 & 65 \\
\hline People who receive services online & 29 & 59 \\
\hline
\end{tabular}

TABLE 3 KPI of Ukrainian economy

\begin{tabular}{|c|c|c|c|c|c|c|c|c|c|c|}
\hline Indicator & 2021E & 2022E & 2023E & 2024E & 2025E & 2026E & 2027E & 2028E & $2029 E$ & 2030E \\
\hline $\begin{array}{l}\text { Domestic market (ICT consumption), } \\
\text { billion dollars }\end{array}$ & 2.0 & 2.5 & 3.0 & 4.5 & 6.0 & 8.0 & 10.0 & 12.0 & 14.0 & 16.0 \\
\hline Impact on GDP, percentage of growth & +0.5 & +1 & +2 & +3.5 & +4.5 & +6 & +7.5 & +9 & +11 & +14 \\
\hline
\end{tabular}

TABLE 4 Share of the digital economy in Ukraine's GDP (KPI)

\begin{tabular}{|c|c|c|c|c|c|c|c|c|c|c|}
\hline Indicator & 2021E & 2022E & 2023E & 2024E & 2025E & 2026E & 2027E & 2028E & 2029E & $2030 E$ \\
\hline Share of the digital economy in total GDP & 3 & 5 & 8 & 11 & 15 & 20 & 28 & 40 & 52 & 65 \\
\hline
\end{tabular}


technologies: finance, agriculture, industry, transport, medicine, insurance, tourism and dozens of others.

Official statistics do not count the volume of the digital economy in Ukraine. Therefore, imagine KPI, set out in the table below, based on their own estimates (based on numerous studies by international organizations on the impact of digitalization).

Ukraine's digital development indicators should be considered in the following ways (Otenko, Chepeliuk, 2018):

- digital infrastructure coating (penetration/coverage);

- absorption, that is, the level of use of digital technologies (scrap or deep, superficial or in key business processes)

- frequency of use (intensity).

However, coverage is a key issue in Ukraine, as it is from there that the diffusion of technologies and their use by users begins.

\section{Conclusions}

As a result, the main problems of the development of the Ukrainian economy in the context of global transformational processes related to digitalization are analysed. For Ukraine, digitalization may become a spur to modernize the economy and overcome the crisis. An analysis of the current state of its development shows that the further introduction of digital technologies in all sectors of the economy is impossible without the removal of obstacles to their development: inadequate protection of intellectual property rights, high investment risks, low levels of cybersecurity and piracy.
Other problems include the lack of motivation to digitize both the society and the company staff. Government policies should aim to enable the introduction and use of new digital tools, instead of traditional ones, among citizens and businesses, and to make digital technologies accessible to consumers, thereby increasing demand for them. As far as business is concerned, such transformations require many resources, from economic to cultural. Only then the benefits of digitalization be effectively optimized while minimizing its risks. The reorientation of Ukraine towards innovative development is possible only under conditions of large-scale implementation of innovative projects, and the transition to an innovative model of economic growth is one of the main tasks of the State in the near future. However, as the study shows, the dynamics of Ukraine's innovative potential and ratings for 2015-2020 are rather slow and in some respects negative, which, coupled with political instability, reduces the investment attractiveness of domestic firms.

The article presents the digital business transformation model, which proves that the processes of digitalization require the structuring and systematization of the respective processes in the organizations, their components and the relationships between them. Timely adaptation of performance management in a dynamic information environment. The development and introduction of e-commerce in Ukraine has been defined, which confirms the imperfection of the domestic regulatory base on business digitalization, the weakening of the economy as a whole, and the inactivity of the leadership of the organizations in the introduction of innovative technologies for business development.

\section{References}

[1] McKinsey \& Company (2020). E-source: https://www.mckinsey.com/\#

[2] Gartner (2020). E-source: https://www.gartner.com/en

[3] Strategy Partners (2020). E-source: https://strategy.ru

[4] Otenko, I. P. (2008). Strategichni prioriteti pidpriemstva [The strategic priorities of the enterprise]. Kharkiv: HNEU. E-source: https://scholar.google.com.ua/citations?user=7RybB2IAAAAJ\&hl=ru\#d=gs_md_cita-d\&u=\%2Fcitations\%3Fview_ op\%3Dview_citation\%26hl\%3Dru\%26user\%3D7RybB2IAAAAJ\%26citation_for_view\%3D7RybB2IAAAAJ\%3A9yKSN-GCB0IC\%26tzom\%3D-120

[5] Otenko, I. P., \& Chepeliuk, M. I. (2018). Korporatyvna kultura: mizhnarodnyi ta transformatsiinyi aspekty [Corporate culture: international and transformational aspects]. Kharkiv: HNEU. E-source: http://repository.hneu.edu.ua/ bitstream/123456789/20079/1/2018-\%20Отенко20I\%20П\%2С\%20Чепелюк\%20M\%20I.pdf

[6] PWC (2020). Navigating the rising tide of uncertainty: 23rd Annual Global CEO Survey. E-source: https://www.pwc.com/ gx/en/ceo-survey/2020/reports/pwc-23rd-global-ceo-survey.pdf

[7] Sondergaard, P. (2019). Did Digital Die? E-source: https://www.sondergaardgroup.com/post/did-digital-die

[8] Casselman, R. M., \& Samson, D. (2007). Aligning knowledge strategy and knowledge capabilities. Technology Analysis \& Strategic Management, 19(1), 69-81.

[9] Venkitachalam, K., \& Willmott, H. (2016). Determining strategic shifts between codification and personalization in operational environments. Journal of Strategy and Management, 9(1), 2-14.

[10] von Krogh, G., Nonaka, I., \& Aben, M. (2001). Making the most of your company's knowledge: a strategic framework. Long Range Planning, 34(4), 421-439.

[11] Dragicevic, N., Ullrich, A., Tsui, E., \& Gronau, N. (2019). A conceptual model of knowledge dynamics in the industry 4.0 smart grid scenario. E-source: https://lswi.de/assets/downloads/publikationen/108/Ullrich-A-Conceptual-modelof-knowledge-dynamics.pdf

[12] Zimmermann, A., Schmidt, R., Jugel, D., \& Möhring, M. (2015). Adaptive Enterprise Architecture for Digital Transformation. In European Conference on Service-Oriented and Cloud Computing. Springer International Publishing, p. 308-319.

[13] Vial, G. (2019). Understanding digital transformation: A review and a research agenda. The Journal of Strategic Information Systems, 28(2), 118-144.

[14] Briel, F. V., Davidsson, P., \& Recker, J. (2018). Digital technologies as external enablers of new venture creation in the IT hardware sector. Entrepreneurship Theory and Practice, 42(1), 47-69.

[15] Giones, F., \& Brem, A. (2017). Digital technology entrepreneurship: A definition and research agenda. Technology Innovation Management Review, 7(5), 44-51. 
[16] Nambisan, S., Wright, M., \& Feldman, M. (2019). The digital transformation of innovation and entrepreneurship: Progress, challenges and key themes. Research Policy, 48(8), 1-9.

[17] Sturgeon, T. J. (2019). Upgrading strategies for the digital economy. Global Strategy Journal, 11(7), 1-24.

[18] Polozhikhina, M. A. (2018). The national models of the digital economy. E-source: https://cyberleninka.ru/article/n/ natsionalnye-modeli-tsifrovoy-ekonomiki

[19] Henriette, E., Mondher, F., \& Boughzala, I. (2015). The Shape of Digital Transformation: A Systematic Literature Review. E-source: https://www.researchgate.net/profile/Imed_Boughzala2/publication/301524030_The_Shape_of_Digital_Transformation_A_Systematic_Literature_Review/links/5719d22208aed43f63235ab6/The-Shape-of-Digital-Transformation-A-Systematic-Literature-Review.pdf

[20] Billon, M., Lera-Lopez, F., \& Marco, R. (2010). Differences in digitalization levels: a multivariate analysis studying the global digital divide. E-source: https:/www.readcube.com/articles/10.1007\%2Fs10290-009-0045-y 